\title{
Lepra: combatimos la enfermedad no a los que la sufren
}

\author{
Pablo A. Vial y Rafael Araos
}

\author{
Leprosy: we figth the disease not those who suffer from it
}

\section{$\mathrm{L}$} a confirmación de tres casos de lepra en Chile durante este año 2017, todos ellos importados, ha producido alarma en la población e interés por conocer el estado de esta enfermedad en el mundo. La lepra es una enfermedad de notificación obligatoria en Chile y, de acuerdo a la información disponible en el Departamento de Epidemiología del Ministerio de Salud, "en los últimos años, se han notificado 1 a 2 casos anuales importados". Históricamente no hay registro de casos autóctonos en el territorio continental. En el pasado, sólo se han documentado casos en Isla de Pascua, donde fue introducida probablemente desde Tahiti, a fines del siglo 19; actualmente no hay casos en la isla con enfermedad activa.

A falta de presencia de lepra en Chile, lo que la población (y la mayoría del personal de salud), conoce sobre la enfermedad son los dramáticos relatos y testimonios gráficos históricos de llagas y mutilaciones y el temor y odiosidad con que se estigmatizaba y marginaba a los que la sufrían. Esto no es así en países en que todavía esta infección es endémica, donde hay una adecuada capacitación para realizar un diagnóstico oportuno y utilizar el tratamiento efectivo que cura la enfermedad y evita el avance de las lesiones, deformidades y amputaciones. Consecuentemente, estos pocos casos diagnosticados en Chile nos ayudarán a ponernos al día y recordar que combatimos enfermedades y no a los que las sufren.

La lepra es una infección crónica causada por Mycobacterium leprae; este bacilo ácido alcohol resistente, tiene el mérito de ser la primera bacteria descubierta como agente causal de una enfermedad humana. Este descubrimiento fue realizado por el médico noruego Gerhard Henrik Armauer Hansen en 1873, bajo la convicción de que se trataba de una enfermedad contagiosa, a partir del estudio en el microscopio de lesiones de piel. En éstas describió estructuras similares a varas pequeñas, que más tarde se denominarían bacilo de Hansen. No le fue posible cultivarlo in vitro entonces, imposibilidad que se mantiene hasta el día de hoy.

Si bien Hansen pudo demostrar la naturaleza infecciosa de la enfermedad que hoy lleva su nombre, la forma de transmisión ha permanecido elusiva. Para la identificación de la vía de contagio han conspirado el que $M$. leprae es de lento crecimiento (su período de replicación se estima en 14 días), el que la enfermedad tenga un período de incubación prolongado (entre 3 y 5 años con un rango entre 1 y 20 años) y el que sólo una fracción pequeña de los infectados desarrolle manifestaciones clínicas (menos de $5 \%$ de la población sería genéticamente susceptible a desarrollar la enfermedad). Es poco probable que la infección se transmita por contacto con la piel, ya que esta micobacteria no es capaz de atravesar piel intacta. Al mismo tiempo, se ha demostrado que la fuente más probable de infección son las secreciones nasales, en las que -en pacientes con compromiso mucoso- se han identificado sobre 1 millón de bacterias por $\mathrm{ml}$, las que permanecen viables en el ambiente hasta por $24 \mathrm{~h}$. Las personas genéticamente relacionadas que viven bajo el mismo techo (hijos, padres, hermanos) tienen mayor riesgo de contraer la infección. No así la esposa o esposo del caso.

El bacilo de Hansen es un patógeno intracelular que infecta principalmente macrófagos y las células de Schawn, puede replicarse también en células endoteliales, e infectar, además de piel, mucosas y nervios, tejidos como músculos, cerebro, ojo y testículos. Sin embargo, raramente es letal y sus principales consecuencias son deformidades e incapacidad física. Si hubiese que hacer una síntesis, esta es una enfermedad de piel y mucosas y de los nervios periféricos, tejidos donde radican las principales manifestaciones clínicas.

La expresión clínica de la infección y la clasificación de la enfermedad es dependiente del balance entre replicación de la bacteria y el tipo e intensidad de la respuesta inmunológica. Los extremos clínicos son la lepra tubercoloídea que se presenta como lesiones de piel localizadas (máculas ovoideas hipopigmentadas con bordes definidos) en las que se encuentran muy pocas bacterias (paucibacilar), y predomina la respuesta inmune tipo Th1 con fuerte componente celular (IL2, IFN- $\gamma$ ) y escasa respuesta humoral, y por otro lado, la lepra lepromatosa con múltiples lesiones de piel, generalmente simétricas (máculas, placas, nódulos, pápulas solevantadas y con bordes poco definidos), con alto número de bacterias en la histología (multibacilar), en que la respuesta inmunológica tipo TH2 se caracteriza por ausencia de respuesta celular y una importante respuesta humoral. Las lesiones de la piel no son dolorosas ni pruriginosas, por el contrario, presentan hipoestesia al dolor, calor y tactil.
Instituto de Ciencias e Innovación en Medicina. Facultad de Medicina Clínica AlemanaUniversidad del Desarrollo. Recibido: 10 de agosto de 2017. Correspondencia a: Pablo A. Vial pvial@udd.cl 
Esto representa el tropismo de la bacteria por nervios periféricos (sensitivos y motores). Entre los dos extremos descritos existen tres estados intermedios: tubercoloídea borderline, borderline, y lepromatosa borderline, según sea el balance entre respuesta celular y replicación del bacilo. El compromiso de la piel incluye la destrucción de glándulas sudoríparas y folículos pilosos en las lesiones, y dado que la bacteria requiere de temperaturas bajas $\left(27-30^{\circ} \mathrm{C}\right)$ para replicarse, compromete áreas de la piel de menor temperatura (cara, tórax, extremidades), sin afectar las axilas, el cuero cabelludo ni las ingles. Todos estos elementos entregan claves clínicas para el diagnóstico: lesiones de piel de diversa morfología, en áreas específicas, con compromiso sensitivo, pérdida de folículos pilosos, sin sudoración. El compromiso de nervios motores también debe buscarse orientándose a sutiles pérdidas de fuerza en las extremidades.

El diagnóstico de la lepra es importante para definir el tratamiento y se basa en la correcta clasificación clínica de los pacientes y en el examen histológico de la piel. Desde un punto de vista clínico se debe clasificar la lepra dentro del espectro descrito que va desde la lepra tuberculoídea hasta la lepra lepromatosa (en https://www.cdc.gov/ leprosy/index.html y http://www.who.int/lep/resources/ Guide_S.pdf puede encontrase una guía simple para el diagnóstico clínico). El diagnóstico de laboratorio se basa en frotis de cortes de piel (habitualmente de seis sitios) o mediante biopsia de piel (borde de la lesión incluyendo dermis y epidermis) que tiene mayor sensibilidad. El examen microscópico de las lesiones permite clasificar los casos como paucibacilares (nula o baja presencia de bacilos) o mutibacilares (múltiples bacilos) con lo que se determina la combinación de medicamentos y duración del tratamiento. Existen métodos serológicos (anticuerpos contra el antígeno PGL-1) que tienen bajo rendimiento. Se han desarrollado técnicas moleculares basadas en reacción de polimerasa en cadena (RPC) para identificar el $M$. leprae en cortes de piel, secreciones nasales y sangre, utilizadas como complemento a la biopsia.
El tratamiento de la lepra sigue los mismos principios que la terapia de otras micobacteriosis, involucrando esquemas combinados de antimicrobianos que se usan por tiempo prolongado. El tratamiento con antimicrobianos cura la lepra, detiene la transmisión y previene el desarrollo de discapacidades. Los fármacos más utilizados son dapsona junto a rifampicina (lepra paucibacilar) y clofazimina que se agrega en casos multibacilares. Además, se usan inmunomoduladores como corticosteroides y talidomida en casos de estados reaccionales, que pueden ocurrir en cualquier tipo de lepra e incluyen lesiones inflamatorias de la piel (reacciones tipo 1) y más profundas tipo eritema nodoso (reacciones tipo 2).

Desde los años 90, la Organización Mundial de la Salud (OMS) impulsa una estrategia cuyo objetivo es reducir y finalmente eliminar la lepra del mundo. Parte de este esfuerzo es dar acceso gratuito y proveer de terapia multi-drogas a todo el que lo necesite. La campaña ha sido exitosa. En cerca de 20 años, el número de casos en el mundo se ha reducido desde 700.000 casos nuevos al año (período 1980-2000) a 170.000 casos notificados el 2015. De los 122 países donde la lepra era endémica, todos han alcanzado una prevalencia menor o igual a 1 caso por 10.000 habitantes. Globalmente India, Brasil e Indonesia concentran el $80 \%$ de los casos de lepra en el mundo; otros 14 países en conjunto reportan un 15\% adicional: Angola, Bangladesh, China, República Democrática del Congo, Etiopía, Madagascar, Mozambique; Myanmar, Nepal, Nigeria, Filipinas, Sri Lanka, Sudan y Tanzania. En su documento Estrategia Global Lepra 2016-2020, la OMS establece una visión: cero enfermedad, cero transmisión, cero discapacidad por lepra, cero estigma y discriminación, proponiendo políticas sanitarias para alcanzar estas metas.

Con esta inspiración y en el escenario actual de creciente movilidad de los individuos en el mundo, debemos procurar la educación de nuestra población, la formación de los profesionales de la salud y el desarrollo de políticas públicas en el contexto de una salud global. 